\title{
A Critical Approach to Macrosocial Determinants of Population Health: Engaging Scientific Realism and Incorporating Social Conflict
}

\author{
Edwin Ng • Carles Muntaner
}

Published online: 16 January 2014

(C) Springer International Publishing AG 2014

\begin{abstract}
The advancement of theory and research on macrosocial determinants of health has been identified as a promising path for future social epidemiology. In this commentary, we outline how macrosocial epidemiology can advance in two critical ways: (1) engaging scientific realism, and (2) incorporating social conflict. The first describes how scientific realism can be effectively applied within macrosocial epidemiology to identify the specific contexts in which social mechanisms are triggered, which in turn, generate health outcomes. Engaging scientific realism fosters a deeper understanding on how and why macrosocial factors, processes, and institutions are causally linked to population health. The second makes the case to incorporate a social conflict paradigm into macrosocial epidemiology. Thinking in terms of social conflict allows us to view social structures as inequalitygenerating mechanisms, and re-orients our public health efforts toward social change, including for example, taking action on unequal political, economic, and cultural relations.
\end{abstract}

Keywords Context $\cdot$ Critical Sociology $\cdot$ Macrosocial epidemiology $\cdot$ Scientific realism $\cdot$ Health inequalities . Mechanisms · Outcome patterns · Population health · Social change $\cdot$ Social conflict $\cdot$ Social structures . Unequal power relations

\footnotetext{
E. $\mathrm{Ng}$

Centre for Research on Inner City Health, Li KaShing Knowledge Institute, 209 Victoria Street, 3rd Floor, Toronto, Ontario M5B 1C6, Canada

e-mail: nged@smh.ca

\section{Muntaner $(\bowtie)$}

Bloomberg School of Nursing, Dalla Lana School of Public Health, University of Toronto, 155 College Street, Suite 386, Toronto, Ontario M5T 1P8, Canada

e-mail: carles.muntaner@utoronto.ca
}

\section{Introduction}

Recently, Galea and Link expressed concern about the usefulness of social epidemiology to contribute new and relevant knowledge on population health, and suggested several paths for the future of social epidemiology $[1 \bullet \cdot]$. One path called for undertaking more research on macro-level factors, processes, and institutions, including for example, globalization [2], political economic systems [3], and macroeconomics [4••]. Indeed, this suggestion to advance macrosocial epidemiology is both timely and astute, since our knowledge based on largescale determinants of health fails in comparison to how much we know about mid-level factors such as income and education [5]. Why has more attention been paid to downstream determinants rather than upstream ones? Galea and Link offer two possible reasons for this discrepancy $[1 \bullet \bullet$. First, research on macrosocial determinants is assumed to be more difficult. Second, it is further assumed that social epidemiologists lack the necessary knowledge and skills to study the connections between macro-level factors and health. On epistemological and social justice grounds, we find these reasons unsatisfactory.

If social epidemiologists are expected to produce knowledge that minimizes preventable deaths and alleviates human suffering for all, we'd argue that our discipline has the professional responsibilities to undertake research that is inherently hard and complex (e.g., adopting a macro-level orientation and asking questions on how social structures generate health inequalities across time and place), and to learn new theory and skills to understand the connections between macro-level phenomena and population health (e.g., becoming familiar with sociological theories that explain why some groups are able to dominate and exploit others for their own political, economic, and cultural gain). On these grounds, the future of social epidemiology would benefit from adopting a macro-level orientation, as well as applying a critical perspective [6•, 7-9]. Having previously argued for the need for politics and economics to be 
incorporated into dominant explanations of population health [10], in this commentary, we apply a critical perspective to macrosocial epidemiology that engages scientific realism and incorporates social conflict. To better understand the perspectives advocated here, it is useful to briefly describe, compare, and contrast scientific realism and social conflict with other (philosophical) approaches and (sociological) paradigms.

Scientific realism is a philosophical approach to the social sciences that can be applied to macrosocial epidemiology to identify the patterns between specific contexts, causal mechanisms, and health outcomes [8, 11-13, 14••]. Within social epidemiology, there are at least four epistemological approaches that researchers implicitly or explicitly adopt: pragmatism (e.g., the truth of a concept or proposition relates to its practical effects), empiricism (e.g., also known as positivism-all knowledge derives from experience as against a priori categories), rationalism (e.g., deductive reasoning is the ultimate test of knowledge), and realism (e.g., reality is ontologically independent of practical effects, sensory experience, and rational beliefs). The key idea is that different theories of knowledge matter because epistemologies shape, influence, and determine how topics such as 'race and health' are conceptualized, tested, and interpreted. For example, pragmatists include race variables in their studies for reasons related more to their academic utility, convention, and consequences (e.g., race is investigated because "it works" in a statistical sense), rather than for reasons that implicate prejudice, stereotypes, and racism as health inequality-generating mechanisms. By comparison, the treatment of race by empiricists is guided by scientific methods (e.g., any hypothetical effect of race on health must be directly and systematically observed) and empirical evidence (e.g., all associations between race and health must be verified and replicated with sensory experiences in the form of valid and reliable data). Given the dominance of empiricism in public health, the extant literature is filled with studies that show race-health associations and few that identify causal mechanisms or recommend social interventions. Among rationalists, the key to understanding how race affects health requires deductive reasoning and a priori probabilities. The curious implication is that rationalists are likely to theorize about race and health without the support of empirical data to support their claims. In sharp contrast, scientific realists begin with the acknowledgement that race and health are connected in complex ways that exist independent of our senses [11]. For example, existing studies find individual and institutional forms of racism contribute to producing and perpetuating health inequalities. The key distinction among realists is that these realities exist over and above our pragmatic, empirical, and rational understanding of them. From a realist perspective, the challenge is to build and refine theory about the nature of race and health, identify immeasurable mechanisms and causal powers that link race and health, and generate theory- and data-driven statements about 'unobservables' as 'observables' [15••]. Realism allows social epidemiologists to gain a deeper understanding of how, why, and under what contexts macrosocial determinants improve or harm population levels of health $[16,17,18 \cdot]$.

In terms of social conflict, this is a sociological paradigm based on the idea that society is a complex system characterized by inequality, tension, and conflict. These features have the potential to trigger various kinds of social change that may affect population health, including labor strikes, political strife, and social justice movements for racial and gender equality. Guided by this paradigm, macrosocial epidemiologists examine how unequal power relations based on social class, race, ethnicity, and gender (e.g., exploitative employment relations, racism, sexism) are causally linked to unequal distributions of valuable resources (e.g., private ownership of productive means, exclusionary educational mechanisms, and intergenerational transfers of wealth create socioeconomic inequalities in the first place), which taken together, generate unfair and avoidable health inequalities. More importantly, this paradigm encourages public health researchers to go beyond the exercise of identifying and replicating significant macro-level associations. The real value of incorporating social conflict into macrosocial epidemiology lies in its emphasis on challenging major patterns of social inequalities, with the potential to narrow, and possibly eliminate, social inequalities in health.

Social conflict is advocated here in favor of structural functionalism, the dominant and non-critical approach commonly used in macrosocial epidemiology. Rather than interrogating major patterns of inequality, epidemiologists who adopt structural functionalism are more concerned with documenting the health consequences of macro-level phenomena. It is not an exaggeration to say that most macrolevel studies in social epidemiology reflect such an orientation. Consequently, most epidemiological studies: (a) adopt uncritical positions on existing social structures (e.g., socioeconomic position is presented as the fundamental cause of health inequalities [19] in favor of capitalist relations that explain how inequalities in both social class and SEP are generated) [20]; (b) assume that society and its interrelated parts operate more or less 'naturally' (e.g., relations between the rich and poor, whites and racial minorities, men and women are relatively 'fixed'); (c) overlook the political, economic, and cultural ways in which social inequalities are constructed over time and across place (e.g., dominant groups protect their privileges by supporting the status quo); (d) emphasize on social stability and cohesion in favor of social conflict and social change (e.g., accept welfare state capitalism and ignore power imbalances between the state/employers and citizens/employees); and (e) display conservatism in their findings and recommendations (e.g., micro- or mid-level interventions are often suggested to tackle macro-level 
phenomenon). Once more, in sharp contrast, incorporating social conflict into our thinking and practice encourages us to view social structures as inequality-generating mechanisms, and re-orients our public health efforts toward challenging unequal power relations such as political power, economic exploitation, and dominant cultural beliefs [3, 21••, 22].

Before advancing these arguments, we first provide a brief rationale on the importance and value of macrosocial determinants to understanding and improving population health.

\section{Macrosocial epidemiology: Moving Upward to Improve Population Health}

The supporting rationale to establish macrosocial epidemiology as a major program of future scholarship is two-fold. First, existing studies confirm that not all causes of population health and health inequalities can be explained by downstream factors $[3,23]$. The key idea is that some determinants of population health exist at the level of social systems and social structures [3, 24], and thus require a macro-level orientation. Because we are seeking to explain why some entities are healthier than others, we should adopt an upstream approach that explains how health inequalities are generated in the first place and reproduced over time through unequal power relations. In this respect, macrosocial approaches to population health differ from prevailing mid-level approaches that focus on stratified attributes and conditions (e.g., social gradients in health studies that have been replicated for decades) [25]. From a macrosocial perspective, social gradients in health do not simply reflect the fact that some individuals and groups obtain more education, earn more money, and occupy better jobs than others. Instead, health inequalities reflect unequal relations located at a macro-level, and result from social mechanisms that are often unobservable [15••, 26]. For example, private ownership of productive resources empowers some persons and firms to appropriate the surplus labor of others (e.g., capitalist relations in the form of profits) [27]; exclusionary mechanisms enable some groups to severely restrict access to certain economic opportunities (e.g., opportunity-hoarding relations in the form of educational credentials) [28]; and discriminatory beliefs and practices often empower certain groups to gain unfair political, economic, and cultural advantages (e.g., cultural relations in the form of sexism, racism, heterosexism, ableism, ageism, class bias) [29]. The research implication is that if unequal power relations are macrosocial determinants of health, then social epidemiologists should direct their research gaze upward to study macrosocial phenomena.

Second, the advantage of focusing on macrosocial determinants of health, or more "distal" and "upstream" causes [30, $31]$, is that greater improvements in population health may be achieved since most disease cases arise among those outside the tail of high risk [32]. As Rose argued: "[T]o find the determinants of prevalence and incidence rates, we need to study characteristics of populations, not characteristics of individuals" [33: p. 428]. Yet, the dominant approach in social epidemiology is to concentrate on the attributes and conditions of people, and to compare the characteristics of these people along a number of mid-level variables such as socioeconomic position, income inequality, and social cohesion [34]. At best, these studies recommend universal policy solutions that increase the availability of social determinants of health (e.g., increasing minimum wages, freezing tuition rates, improving occupational safety). At worst, these studies overlook macro-level phenomena, and offer causal explanations that implicate communities and groups for their own poor health (e.g., communities and groups with poor health possess insufficient levels of social cohesion and communal trust) [35]. In contrast, macrosocial approaches to population health enable us to challenge taken-for-granted assumptions (e.g., narrowing social gradients alone will not achieve health equity), increase our awareness of how social structures affect population health (e.g., income and health inequalities are inherent features in capitalist economies), and promote a much-needed 'public health imagination' (e.g., thinking in a way that transforms personal health problems into political and public issues) [36]. By implication, macrosocial approaches to improving population health involve more than simply increasing the availability of health-promoting resources. In addition to stressing the importance of social determinants of health, macrosocial approaches involve large-scale interventions and movements that redress exploitative, exclusionary, and dominative mechanisms (e.g., increasing workplace democracy, strengthening public institutions at the expense of private interests, and passing affirmative action legislation) [21••, 27].

\section{Engaging Scientific Realism: Macrosocial Contexts, Mechanisms, and Outcomes}

Because existing studies on macrosocial determinants of health are largely guided by positivism, macrosocial epidemiology tends to produce more 'black-box' descriptions than explanatory mechanisms, or research that links explanans and explanandum $[12,13,14 \bullet \cdot]$. Often times, black-box explanations are presented in the form of statistical models, and explanatory mechanisms are understood as regression coefficients [37]. In turn, these coefficients are offered as the casual inference of macrosocial determinants (e.g., indicators of globalization such as exports, multinational corporations, and international lending institutions are predictors of higher infant mortality rates [38]. From a scientific realist perspective, however, the analytical goal is more complex than performing and interpreting regression models. Rather, the 
challenge of scientific realism is to identify the mechanisms that generate macro-level health associations $[13,14 \bullet \cdot, 15 \bullet$, 39••, 40, 41]. In Social Theory and Social Structure, Merton defines mechanisms as "social processes having designated consequences for designated parts of the social structure" and argues that it constitutes the main task of sociology to "identify" mechanisms and to establish under which conditions they "come into being" and "fail to operate" [42; p. 43•, 44-]. In this respect, scientific realism strives to generate deeper and more granular explanations by thinking in terms of generative mechanisms, which in turn, augments our "understanding of why we observe what we observe" [13; p. 9]. In applying this logic to macrosocial epidemiology, the challenge of scientific realism is to identify generative mechanisms that explain how and why macrosocial determinants and population health are casually linked. In question form, for example, "how and why do macrosocial forces, processes, and institutions improve or worsen population health and increase or reduce health inequalities, and under what political, economic, and cultural contexts?"

Given that black-box thinking reflects an empiricist approach, the intellectual goals are to identify plausible connections between independent variables (I) and health outcomes $(\mathrm{O})$, test the systematic direction, strength, and significance of these connections, and determine the degree to which health outcomes change when any one of the macrosocial (independent) variables (I) is varied, while holding other predictors constant. Black-box accounts are the standard in macrosocial epidemiology, and include, for example, dominant programs of research on the health consequences of income inequalities [43•], welfare regime typologies [44•], and democratic states [45*]. In contrast, mechanism-based thinking (scientific realism) involves examining the same causal link between I and $\mathrm{O}$, with the added realist foci of contexts (C) and mechanisms (M). Contexts refer to specific features and settings in which macro-level determinants of health are conceptualized and generative mechanisms are triggered to affect population health [17, 46-48]. Contextual thinking addresses the key questions "for whom" and "in what circumstances" do macrosocial factors, processes, and institutions shape and influence health outcomes. In turn, mechanisms describe what it is about macrosocial determinants that generate population health outcomes $(\mathrm{O})$. The key idea here is that macro-level factors are not the tangible causes of health per se. To be more accurate and precise, macrosocial determinants either provide or withhold the resources that improve or harm health and increase or reduce health inequalities. Because mechanisms are often unobservable and thus immeasurable, the scientific realist tasks for social epidemiologists are three-fold: (1) identify the inner workings of macrosocial determinants of health; (2) build generative theories; and (3) produce a set of theoryand data-driven statements on how and why macrosocial determinants are casually linked to population health.
To make scientific realism less abstract and more concrete, let's review a current example in the extant literature - the macro-level health associations between leftist politics, welfare regimes, and welfare generosity $\left[49 \bullet, 50^{\bullet}\right]$. Guided by a realist framework, we can deconstruct the interactions between politics (e.g., organizations and institutions committed to egalitarian, moderate, or conservative ideologies), regimes (e.g., historical balance of working-class power), and generosity (e.g., state distribution of public goods and social transfers) into their essential contexts, mechanisms, and outcome patterns [17]. Pawson and Tilly [17] describe context-mechanism-outcome patterns using the lettering system (C1) (M1) (O1). Given this, it is not essential that we an explanatory note. It's not a standard in the field of realist evaluation. Since contexts enable and constrain the operation of mechanisms, the political, economic, and cultural contexts of population health are central to generating initial theory. For example, political contexts relevant to population health include open forms of government such as 'democratic states' $\left(\mathrm{C}_{1}\right)$ [51] and constitutional constraints such as 'proportional representation systems' $\left(\mathrm{C}_{2}\right)$ [52]. The historical balance of political power may be germane as well, including for example, 'strength of leftist political parties' $\left(\mathrm{C}_{3}\right)$ $[3,24]$, 'strength of trade unions' $\left(\mathrm{C}_{4}\right)[53,54]$, 'number of female politicians' $\left(\mathrm{C}_{5}\right)$ [55], 'strength progressive social movements' $\left(\mathrm{C}_{6}\right)$ [56], and 'social democratic welfare regimes' $\left(\mathrm{C}_{7}\right)[57,58]$. Macro-levels of health are also dependent on economic contexts such as economic systems, 'capitalist relations' $\left(C_{9}\right)$ [59], policy preferences, 'neoliberal doctrines' $\left(C_{10}\right)$ [60], and economic indicators, 'economic growth' $\left(\mathrm{C}_{11}\right)$ [61] and 'global recessions' $\left(\mathrm{C}_{12}\right)$ [62]. The health impact of cultural contexts may consist of social norms, 'individualist' $\left(\mathrm{C}_{13}\right)$ [63] versus 'collectivist' $\left(\mathrm{C}_{14}\right)$ [64], and dominant ideologies, 'populism' $\left(\mathrm{C}_{15}\right)$ [65] versus 'elitism' $\left(\mathrm{C}_{16}\right)$ [66].

Recall that causal mechanisms are the resources responsible for improving or harming population health and reducing or increasing health inequalities. The critical distinction is that independent variables (I) are not the units of analysis that explain causation. Welfare generosity, for example, has been conceptualized as a macrosocial determinant of health [67•]. However, government expenditures are not causal mechanisms that explain the logic on how and why welfare states shape and influence health outcomes. In realist terms, government expenditures work in different ways in different contexts to trigger various mechanisms $\left(\mathrm{M}_{1}, \ldots, \mathrm{M}_{\mathrm{n}}\right)$, which in turn, affect health outcomes. So what are possible causal mechanisms that explain how and why welfare generosity improves health and reduces health inequalities? Health-promoting resources activated by welfare regimes include, but are not limited to, the 'provision of public goods' $\left(\mathrm{M}_{1}\right)$ (e.g., universal healthcare) [68]; 'protection against labor market risks' $\left(\mathrm{M}_{2}\right)$ (e.g., generous pension and unemployment benefits) [57]; 'institutionalization of acceptable standards of living' $\left(\mathrm{M}_{3}\right)$ (e.g., large stock of social housing) [68]; 'reduction of social 
inequalities' $\left(\mathrm{M}_{4}\right)$ (e.g., generous income maintenance programs) [69]; 'decommodification of labor' $\left(\mathrm{M}_{5}\right)$ (e.g., alleviating the degree to which individuals are forced to sell their labor as commodities) [57]; 'guarantee of social citizenship rights' $\left(\mathrm{M}_{6}\right)$ (e.g., income entitlements are universal and granted for all citizens) [70]; 'defamilization of labor' $\left(\mathrm{M}_{7}\right)$ (e.g., alleviating the degree to which individuals can uphold acceptable standards of living independent of family relationships) [71]; 'protection against psychosocial stress and healththreatening behaviors' $\left(\mathrm{M}_{8}\right)$ (e.g., welfare expenditures buffer against material deprivation' $[72,73]$; and 'investment in public infrastructures' $\left(\mathrm{M}_{9}\right)$ (e.g., redistribution of societal resources for public goods) [74].

Within contexts, mechanisms are activated, resulting in specific health outcome patterns. Health outcome patterns are the intended and unintended interactions and consequences of leftist politics, welfare regimes, and welfare generosity. Scientific realism advises against relying on any single health variable to understand the health effects of macrosocial entities. Instead, the rule of thumb is to consider a wide range of health outcomes to produce a more nuanced understanding of how macrosocial determinants generate multiple outcome patterns over the lifecourse. Although most macrosocial studies remain focused on disease-specific outcomes, existing studies fare much better in terms of life-course stages, finding that politics, regimes, and generosity generate and reproduce population health outcomes during childhood (e.g., infant mortality and low birth weight) $\left(\mathrm{O}_{1}\right)$ [75], adolescence $\left(\mathrm{O}_{2}\right)$ [76], working-age $\left(\mathrm{O}_{3}\right)$ [54], and retirement $\left(\mathrm{O}_{4}\right)$ [77], as well as across sub-groups such as gender $\left(\mathrm{O}_{5}\right)$ [78•]. The notion of outcome patterns runs contrary to the bio-medical tradition of disease-specific investigations; however, thinking in terms of outcome patterns allows us to broaden our approach to understanding and explaining how and why macro-level determinants are linked to multiple public health outcomes.

At its core, scientific realism is about theory-testing and refinement. Identifying context-mechanism-outcome patterns in macrosocial epidemiology represents a major step toward producing a fuller understanding on (a) how macrolevel factors, processes, and institutions (e.g., welfare state capitalism) (b) trigger, authorize, and justify key mechanisms (e.g., employment relations) that (c) generate and reproduce unequal power relations (e.g., capitalist and managerial class versus well-educated and trained middle class versus working class with weak unions versus precarious workers versus working poor) (d) under specific conditions (e.g., global recession within the context of austerity), (e) to bring about predictable levels of population health and health inequalities. Whereas positivism aims to connect and replicate the associations between (a) and (e), scientific realism offers new directions such as (b), (c), and (d), for macrosocial theories of population health.

\section{Incorporating Social Conflict: Unequal Political, Economic, and Cultural Relations}

It suffices to say that the vast majority of research on macrosocial determinants of health favors a purely scientific paradigm more than a social-conflict approach [54, 79]. Guided by the former paradigm, macrosocial epidemiology presumes that social structures simply exist within an orderly system, and that the goals of public health research are to gather empirical data, describe macro-level patterns, and recommend incremental changes [80••]. Consequently, this work tends to be produced for academic audiences, motivated by professional interests, and guided by structural-functional theories (e.g., viewing society as a complex system where social structures work together to ensure productivity and stability such as economic growth) [80••]. Given this, it is not an exaggeration to say that most research on macrosocial epidemiology is non-critical, and that our current knowledge of population health tends to be "overly descriptive ... [and] almost irrelevant to policy debates" [81•].

There are at least three reasons why macrosocial epidemiology qualifies as being 'non-critical'. First, most macro-level epidemiologic studies do not consider the effects of social conflict, or the inherent struggle between individuals and groups over positions of power and valued resources (e.g., political, economic, and cultural) [22]. Second, current research generally makes policy recommendations that are restricted to improving the health of specific groups through targeted programs and services rather than improving the health of populations through universal programs (e.g., universal healthcare, childcare, and post-secondary education) [82]. Third, nearly all work fails to implicate social structures that generate and reproduce inequalities in the first place as macrosocial determinants of health inequalities (e.g., privateproperty rights over means of production; capacity of business owners to acquire profits from subordinated classes; oppressive, dominative, and exploitative histories based on colonial, patriarchal, and racial relations) $[21 \bullet \bullet, 83,84]$.

To advance a more critical understanding of population health, our conceptualization of macrosocial determinants explicitly incorporates the sociological ideas of social structures and social-conflict [ $85 \cdot]$. Here, the emphasis is on how social structures, or relatively stable patterns of social behavior, generate and reproduce different forms of social conflict, which result in unequal political, economic, and cultural relations [85•], which in turn, produce health inequalities. The key idea is that these social structures and social conflicts have the effect of benefiting some groups (e.g., core/wealthy nations; men; heterosexuals; able-bodied; non-retired; business owners) at the direct expense of others (e.g., semi-periphery/middle-income and periphery/low-income nations; visible minorities; women; lesbian, gay, bisexual, transgender; disabled; working class; poor; First Nations) [27, 29, 86]. 
Our argument is that macrosocial epidemiology should integrate some of the central tenets of critical sociology, which focuses on the need for social change to address societal patterns of inequality $[6,9,36]$. By doing so, our discipline can continue to conduct non-critical epidemiology (e.g., which macrosocial determinants shape the risk and occurrence of poor health?"), as well as undertake more consequential and critically-oriented scholarship (e.g., how can social change influence the nature of macro-level determinants in the first place?). In our view, this requires asking questions that actively engage moral and ethical issues $[10,15 \bullet \cdot$. If future research were to incorporate socialconflict and redress moral and ethical issues, macrosocial epidemiology would immediately become more useful, relevant, and even indispensable since unequal power relations would be implicated as a major cause of avoidable and unfair health inequalities. Illustrative questions include, "What are the major macrosocial determinants of economic, gender, and racial inequalities, and how do these unequal power relations affect health?", "How do macro-level forces, processes, and institutions generate health inequalities over time and across place?", "How do health inequalities reflect social conflict, and how can they be reduced through social change?", "How do more powerful and healthier entities protect their privileges and health?", and "How can less powerful and sicker entities challenge the status quo to improve their health?".

Because these questions are inherently value-laden (and somewhat unconventional and controversial), macrosocial epidemiologists committed to social justice should determine whether they are content with documenting and replicating the existence of health inequalities, or willing to use epidemiologic research in a distinctly critical way to learn how social structures operate, generate inequalities, and determine population levels of health. The latter approach offers at least two future directions for critical macrosocial epidemiologists. First, our discipline needs to produce more engaged scholarship that sheds light on how and why macro-level forces, processes, and institutions generate and reproduce health inequalities (e.g., using scientific realism methods to interrogate social conflict) [80••]. Second, our discipline needs to view research as a process of knowledge production as well as an intervention strategy that has the power to reduce unequal power relations (e.g., producing research that informs and brings about needed change).

Both directions converge on the clear need for more macrosocial research that challenges the status quo of existing social structures and transforms the nature of structural inequalities (e.g., taking action on mechanisms that allow, justify, and perpetuate some entities to control, dominate, and exploit others for their own economic gain) [27, 28]. For example, applying a critical approach to macrosocial epidemiology encourages us to conceptualize relational mechanisms such as sexism, racism, heterosexism, ableism, ageism, and classism to understand why powerful groups are healthy and less powerful groups are not [29, 86-88]. Applying the same logic to global health allows us to examine these relational mechanisms, as well as world-system dynamics such as transnational divisions of labor, armed conflicts, capital accumulation processes, and historical trajectories of exploitation [83, 89, 90].

Our version of critical macrosocial epidemiology involves making explicit value judgments about the ways in which society should be changed to improve health (e.g., assisting, protecting, and empowering marginalized and oppressed groups/nations). In doing so, we reject Weber's ideal that researchers remain impartial to produce value-free knowledge [91••]. Conventional macrosocial epidemiologists may object to adopting such clear positions with respect to politics (e.g., supporting egalitarian policies and generous welfare states) [3], economics (e.g., supporting collective bargaining rights and workplace democracy while railing against neo-liberal doctrines and austerity policies) [60], and culture (e.g., supporting pro-gun control measures, pro-choice movements, or affirmative action initiatives) [92]. We counter that research on macrosocial determinants of health is inherently political, economic, and cultural, in that, our research either explicitly or implicitly calls for social change (and better health) or it does not. Because our research topics are intrinsically valuerelevant (e.g., reducing health inequalities involves the removal of exclusionary mechanisms that undermine the advantages of the affluent, credentialed, and privileged), it is impossible and even undesirable for public health researchers to remain value-free in the pursuit of social justice in public health $[91 \bullet \bullet]$. How can we expect to remain objective and apolitical when our profession strives to reduce health inequalities caused by unjust relations? Although it is not possible for public health researchers to remain apolitical, we do have the power to choose which positions to support, the responsibility to conduct high-quality research, and an ethical duty to remain transparent throughout all stages of the research process.

In more practical terms, there are several ways a social conflict paradigm can be effectively applied to macrosocial epidemiology. This includes, but is not limited to, the following value judgments, conceptual shifts, and methodological adjustments:

a) Nurture a public health imagination. Mills [36] emphasized the importance of actively using a "sociological imagination" in helping people understand and engage the social world around them. We believe that macrosocial epidemiologists should apply the same logic to population health that Mills applied to sociology. A "public health imagination" encourages us to think more deeply about commonly held assumptions about macrolevel relationships (e.g., globalization operates as a rising tide that increases and improves the wealth and health of peripheral countries), allows us to consider both the opportunities and constraints of social structures (e.g., 
macro-level realities exist but are mediated by meso- and micro-level mechanisms), and empowers us to be active contributors and users of new public health knowledge (e.g., take advantage of research as a tool for social and political change).

b) Challenge the notion that personal values and public health research are distinct. Given that supposedly "value-free" public health research amounts to telling a "story book picture" of health inequalities [93], macrosocial epidemiologists should embrace health-promoting values such as social justice, equality, and solidarity. By accepting these values as professional obligations, our hope is that future public health research will move beyond producing "value-free" associations (e.g., macrosocial gradients in health) to "value-laden" solutions (e.g., narrowing macrosocial gradients in health involves increasing working-class power and workplace democracy). Navarro and Bambra are two exemplar scholars, who consistently and openly incorporate personal values into their public health research [94, 95].

c) Conceptualize social structures as inequality-generating mechanisms. Rather than viewing social structures such as welfare states and economic systems as stable components that work together to promote stability, macrosocial epidemiologists should investigate how social structures benefit some people at the expense of others. By doing so, we gain a deeper understanding on how welfare state activities and capitalist relations create unequal distributions of political, economic and cultural resources, which in turn, generate health inequalities. Moreover, we will become more familiar with the relational nature of population health-dominant groups are healthier in part because they protect their accumulated privileges, exclude others from accessing scarce opportunities, and ensure that the status quo remains intact.

d) Conduct more applied public health research. More work is needed on the effectiveness and efficacy of new and existing programs, policies, and interventions designed to improve health and reduce health inequalities [96•, 97]. This involves making the transition from being scientific epidemiologists, who describe the nature of health problems, to being applied public health researchers, who focus on how health problems may be solved through political mechanisms and public policies [80••]. For example, the $A t$ Home/Chez Soi is a national project in Canada that is partresearch, exploring ways to help homeless people with mental health problems, and part-social intervention, providing good, quality housing as the first step to recovery [98]. Such work demonstrates the possibility of carrying out applied research that is value-driven, policy-relevant, and committed to solving social problems.

e) Advocate for social change as a public health strategy. Social change refers to the transformation of political, economic, and social institutions over time. The link between social structures that generate health inequalities and social changes that operate as public health interventions captures our core vision of macrosocial epidemiology [22, $27,28]$. In our view, conflicts between employers and

Table 1 Non-critical versus critical macrosocial epidemiology: A summary

Macrosocial Epidemiology

Non-Critical Critical

Theoretical Paradigm

Conceptualization of Macro-level Determinants

Scientific Approach

Research Foci

Primary Audience

Role of Values

Distribution of Political Power

Source of Economic Power

Function of Cultural Power

Population Health Strategies
Structural-functional (e.g., social cohesion)

Macro-level factors work together to promote cohesion and stability

Pure: gather new information, discover new relationships

Describe macro-level patterns between causes and effects

Academics

Value-neutral, objective

Pluralist: highly-dispersed among several interest groups

Stratification: some groups acquire more education, earn more income, and occupy better jobs than other groups

Non-ideological: cultural beliefs, values, and norms are largely overlooked

Rational approach: share findings, make evidence-based recommendations, conduct more research
Social conflict (e.g., social class)

Macrosocial structures create unequal power relations and social inequalities over time

Applied: use research to bring about desired change

Interrogate the relational nature of health inequalities

Policymakers, stakeholders, community groups

Value-relevant, engaged

Power-elite: concentrated among the wealthy

Exploitation: powerful groups control the labor of less powerful groups to its own economic advantage

Ideological: dominant cultural beliefs justify the existence of health inequalities

Advocate for social change: mobilize political action, increase workplace democracy, support social movements 
employees, dominant racial and subordinated racial groups, and men and women, for example, are key drivers of social change in democratic and capitalist societies. Examples abound on how social movements supported by First Nation groups, organized labor, people of color, women, and gay men and lesbians reshape societies in more egalitarian and healthier ways [99]. The macrolevel effects of social change and social movements on population health and health inequalities should no longer be overlooked by social epidemiologists.

To ensure the future relevance of macrosocial epidemiology as an academic discipline, our suggestions are to adopt a more critical approach by nurturing a public health imagination, integrating values and science, implicating structural determinants of inequalities, undertaking more applied research, and appreciating the importance of social change to achieve better health $[80 \bullet \cdot$. To be clear, we are not dismissing non-critical research that examines the connections between macrosocial determinants and population health [23]. To the contrary, non-critical scholarship that establishes macro-level associations is essential; however, our contention is that such work should only serve as starting points for future inquiry. Table 1 summarizes the major differences between 'non-critical' versus 'critical' approaches in macrosocial epidemiology.

\section{Conclusion}

Because research on macrosocial determinants is still maturing [1], our hope is that this emerging sub-discipline will not follow the same intellectual path set by researchers working on midlevel determinants such as socioeconomic position. On one hand, the first epidemiologic studies that found social gradients in health were invaluable [100]. On the other, the reliance on stratification indicators over the past 20 years has contributed to our current lack of understanding on how social gradients in health are generated and what efforts are needed to reduce them. In this commentary, we have provided several promising directions to advance macrosocial epidemiology in new, relevant, and critical ways. Engaging scientific realism challenges our takenfor-granted assumptions between cause and effect, providing new insights on how and why macrosocial determinants matter. Incorporating social conflict into our thinking enables us to assess both the constraints of current epidemiological approaches and the opportunities to use social change to improve health.

Acknowledgements This research was supported (in part) by the European Community's Seventh Framework Program (FP7/2007-2013) to the SOPHIE Project (Evaluating the Impact of Structural Policies on Health Inequalities and Their Social Determinants and Fostering Change), Grant \#278173. The authors also gratefully acknowledge the support of The Canadian Institute for Health Research, Grant \#96566, and the Ontario Ministry of Health and Long-Term Care.

\section{Compliance with Ethics Guidelines}

Disclosures The views expressed in this commentary are the views of the authors and do not necessarily reflect the views of the Ontario Ministry of Health and Long-Term Care.

Conflict of Interest C. Muntaner declares no conflicts of interest. E. Ng declares no conflicts of interest.

Human and Animal Rights and Informed Consent This article does not contain any studies with human or animal subjects performed by any of the authors.

\section{References}

Papers of particular interest, published recently, have been highlighted as:

- Of importance

•- Of major importance

1.• Galea S, Link BG. Six paths for the future of social epidemiology. Am J Epidemiol. 2013;178(6):843-9. Argues that social epidemiology runs the risk of losing its relevance in public health and identifies several important heuristics to guide future scholarship. One heuristic, in particular, calls for more work that examines how truly large-scale (macro-level) factors shape the health of populations. This suggestion serves as the impetus for our current commentary.

2. Florey LS, Galea S, Wilson ML. Macrosocial determinants of population health in the context of globalization. Macrosocial Determinants of Population Health: Springer; 2007. p. 15-51.

3. Navarro V, Muntaner C, Borrell C, Benach J, Quiroga Á, Rodríguez-Sanz M, et al. Politics and health outcomes. Lancet. 2006;368(9540):1033-7.

4.• Stuckler D, Basu S. The Body Economic: Why Austerity Kills: Basic Books; 2013. Presents historical and current evidence on how government stimulus and austerity policies can protect and harm the health of populations, respectively, during economic crises. Serves as an excellent example on how macrosocial epidemiology augments mid-level approaches to produce a more complete understanding of the political and economic determinants of population health and health inequalities.

5. Health WCoSDo. Closing the Gap in a Generation: Health Equity Through Action on the Social Determinants of Health: Final Report of the Commission on Social Determinants of Health: World Health Organization; 2008.

6. Cassano G. What is critical sociology? Crisis, Politics, and Critical Sociology. 2010;17:1. Provides an accessible introduction to nonsociologists on critical sociology and its analytical tools. Explains how the central tenets of critical sociology allow us to better understand the political, economic, and cultural forces that create our social world and generate social inequalities. Helpful for social epidemiologists committed to producing new findings on the roots of health inequalities.

7. Hofrichter R. Health and social justice: Politics, ideology, and inequity in the distribution of disease: Jossey-Bass Inc Pub; 2003.

8. Bhaskar R. A realist theory of science. US: Taylor \& Francis; 2008.

9. Marx K. The marx-engels reader. New York: Norton; 1972.

10. Muntaner C, Chung H. Macrosocial Determinants, Epidemiology, and Health Policy: should politics and economics be banned from 
social determinants of health research? J Public Health Policy. 2008;29:299-306.

11. Bhaskar R. Scientific realism and human emancipation: Routledge; 2009.

12. Hedström P, Swedberg R. Social mechanisms. Acta Sociologica. 1996;39(3):281-308.

13. Hedström P, Swedberg R. Social mechanisms: An analytical approach to social theory: Cambridge University Press. 1998.

14.• Hedström P, Ylikoski P. Causal mechanisms in the social sciences. Annu Rev Sociol. 2010;36:49-67. Defines social mechanisms and reviews the importance of mechanism-based explanations to analytical sociology. Athough the review does not pertain to population health, several potentially relevant ideas are presented, which can be modified and applied to macrosocial epidemiology, including for example, causal mechanisms, nature of explananda, and Mertain's middle-range theory.

15.• Muntaner C. Invited commentary: on the future of social epidemiology - a case for scientific realism. Am J Epidemiol. 2013;178(6):852-7. Makes three novel arguments regarding social epidemiology, which are also applicable to macro-level determinants of health: first, scientific realism can augment the limitations of positivism to better handle the complexities of social epidemiology; second, thinking in terms of social mechanisms allows us to implicate unequal power relations as determinants of health inequalities; and third, public health interventions should actively involve those most affected by social injustices.

16. Dunn JR. Speaking theoretically about population health. J Epidemiol Community Health. 2006;60(7):572-3.

17. Pawson R, Tiller N. Realistic evaluation: Sage. 1997.

18. Pawson R. The science of evaluation: a realist manifesto: SAGE; 2013. Uses realist principles to argue forcefully that the overarching goal of evaluation research is to understand "how', "why", and "when" interventions work. We contend that the same underlying logic can be effectively applied to macrosocial epidemiology to determine what macro-level determinants matter to health, for whom, and under which political, economic, and cultural contexts.

19. Link BG, Phelan J. Social conditions as fundamental causes of disease. Journal of health and social behavior. 1995;35:80-94.

20. Muntaner C, Borrell C, Benach J, Pasarín MI, Fernandez E. The associations of social class and social stratification with patterns of general and mental health in a Spanish population. Int $\mathrm{J}$ Epidemiol. 2003;32(6):950-8.

21.• Muntaner C, Ng E, Vanroelen C, Christ S, Eaton WW. Social Stratification, Social Closure, and Social Class as Determinants of Mental Health Disparities. Handbook of the Sociology of Mental Health: Springer; 2013. p. 205-27. Reviews three major sociological theories to understanding the generation of social inequalities and the reproduction of (mental) health inequalities. Provides theoretical guidance on how to move from gradational (e.g., micro-level) to relational (e.g., meso- and macro-levels) approaches to understanding and explaining health inequalities. Sociological theories reviewed include Weber's idea of 'life chances', or social stratification, the NeoWeberian idea of 'social closure', and the neo-Marxian concept of 'social class'.

22. Navarro V, Muntaner C. Political and economic determinants of population health and well-being: controversies and developments. Baywood: Baywood Publishing Company Inc; 2004.

23. Galea S. Macrosocial determinants of population health. New york: Springer; 2007.

24. Navarro V, Shi L. The political context of social inequalities and health. Social Science \& Medicine. 2001;52(3):481-91.

25. Lynch J, Kaplan G. Socioeconomic position. Social epidemiology. New York: Oxford University Press; 2000.

26. Muntaner C. Invited commentary: social mechanisms, race, and social epidemiology. 1999.
27. Wright EO. Class counts: comparative studies in class analysis. Cambridge: Cambridge University Press; 1997.

28. Tilly C. Durable inequality. California: University of California Press; 1998

29. Krieger N. Discrimination and health. Social epidemiology. Oxford: Oxford University Press; 2000.

30. McKinlay JB. A case for refocusing upstream: the political economy of illness. Applying behavioral science to cardiovascular risk. 1975:7-17.

31. McKinlay JB, Marceau LD. POLITICS OF PUBLIC HEALTHUpstream Healthy Public Policy: Lessons from the Battle of Tobacco. Int J Health Serv. 2000;30(1):49-70.

32. Rose G. The strategy of preventive medicine. The strategy of preventive medicine. 1992.

33. Rose G. Sick individuals and sick populations. Int J Epidemiol. 2001;30(3):427-32.

34. Raphael D. Social determinants of health: present status, unanswered questions, and future directions. Int J Health Serv. 2006;36(4):651-77.

35. Muntaner C, Lynch J. Income inequality, social cohesion, and class relations: a critique of Wilkinson's neo-Durkheimian research program. Int J Health Serv. 1999;29:59-82.

36. Mills CW. The sociological imagination. Oxford: Oxford University Press; 2000.

37. Greenland S, Gago-Dominguez M, Castelao JE. The value of riskfactor (" black-box") epidemiology. Epidemiology. 2004;15(5): 529-35.

38. Shandra JM, Nobles J, London B, Williamson JB. Dependency, democracy, and infant mortality: a quantitative, cross-national analysis of less developed countries. Social Science \& Medicine. 2004;59(2):321-33.

39.• Astbury B, Leeuw FL. Unpacking black boxes: mechanisms and theory building in evaluation. Am J Eval. 2010;31(3):363-81. Provides additional clarification on the concept of mechanismbased thinking within the social sciences. Useful for macrosocial epidemiologists interested in how and why macro-level determinants matter for population health. The key implications for the study of macro-level determinants of health are that causal mechanisms tend to be hidden (e.g., positivism cannot capture mechanisms through measurement), sensitive to variations in context (e.g., macrosocial determinants have differential effects on health depending on political, economic, and cultural contexts), and generate health outcomes (e.g., macro-level measures such as welfare generosity do not cause health outcomes per se but generate resources that improve or cause harm)

40. Sayer A. Method in social science: A realist approach. London: Routledge; 1992.

41. Archer MS. Realist social theory: The morphogenetic approach. Cambridge: Cambridge University Press; 1995.

42. Merton RK. Social theory and social structure. 1968.

43. Wilkinson RG, Pickett K, The spirit level: Bloomsbury Press; 2011. Makes the powerful claim that income inequality, or the gap betweein the affluent and poor, is the single most important factor in determining the level and degree of population health and health inequalites among wealthy nations. To its credit, this work adopts a clear macrosocial determinants of health approach and makes a compelling case for equalizing distributional outcomes. Because of its singular focus on income inequality, however, Wilkinson and Pickett tend to overlook the the importance of political, economic, and cultural contexts as well as causal mechanisms based on exploitation and domination.

44. Brennenstuhl S, Quesnel-Vallée A, McDonough P. Welfare regimes, population health and health inequalities: a research synthesis. J Epidemiol Community Health. 2012;66(5):397-409. Reviews 33 empirical studies that apply welfare regime theory in comparative health research between 1994 and 2011. Concludes that health 
differences by welfare regime are inconsistent with welfare regime theory (e.g., Nordic countries are not always healthier than Conservative nations, and both of these regimes are not always healthier than Liberal countries). Suggests that hypotheses based on welfare regime typologies are subject to the limitations of 'blackbox explanations!

45. Mackenbach JP, Hu Y, Looman CW. Democratization and life expectancy in Europe, 1960-2008. Social Science \& Medicine. 2013. Investigates whether democratization improves population health, measured by life expectancy and cause-specific mortality rates, among Southern and Central and Eastern European countries across two time periods. Using pooled, cross-sectional timeseries analyses with country-fixed effects, the authors find that short-term changes in democracy had a positive effect on population health during the 1960-1990 period; however, no such effect was observed during the 1987-2008 period. Because of its black-box approach, the internal workings on how and why democratization influences population health remain unknown.

46. Pawson R. Evidence-based policy: The promise ofrealist synthesis'. Evaluation. 2002;8(3):340-58.

47. Pawson R, Greenhalgh T, Harvey G, Walshe K. Realist synthesis: an introduction. ESRC Research Methods Programme Manchester: University of Manchester. 2004.

48. Pawson R, Greenhalgh T, Harvey G, Walshe K. Realist review-a new method of systematic review designed for complex policy interventions. Journal of health services research \& policy. 2005;10 suppl 1:21-34.

49. Muntaner C, Borrell C, Ng E, Chung H, Espelt A, Rodriguez-Sanz $\mathrm{M}$, et al. Politics, welfare regimes, and population health: controversies and evidence. Sociology of health \& illness. 2011;33(6): 946-64. Informed by a political economy of health and welfare regimes framework, the authors locate and synthesize 73 empirical and comparative studies on politics and health. Central findings are four-fold: first, left and egalitarian political traditions have a salutary effect on population health; second, democratization also has a positive and large impact on health; third, social democratic nations tend to fare best with respect to absolute health outcomes, yet consistently in terms of health inequalities; and fourth, indicators of globalizations such as trade, foreign investment, and national debt are negatively associated with population health.

50. Pega F, Kawachi I, Rasanathan K, Lundberg O. Politics, policies and population health: A Commentary on Mackenbach and McKee (2013). Social Science \& Medicine. 2013. Reflects on the emerging field of political epidemiology, and distinguishes three macro-level approaches to population health: welfare regime, politics, and individual policy. Emphasizes what the individual policy approach adds to our knowledge base: testing casualty with natural experiments, proposing effective policy interventions, and wide applicability to all nations.

51. Franco Á, Álvarez-Dardet C, Ruiz MT. Effect of democracy on health: ecological study. BMJ: British Medical Journal. 2004;329(7480):1421.

52. Bogdanor V. Proportional Representation: Election Reform Society; 1992.

53. Esping-Andersen G. The three worlds of welfare capitalism. Cambridge: Polity Press Cambridge; 1990.

54. Muntaner C, Lynch JW, Hillemeier M, Lee JH, David R, Benach $\mathrm{J}$, et al. Economic inequality, working-class power, social capital, and cause-specific mortality in wealthy countries. Int $\mathrm{J}$ Health Serv. 2002;32(4):629-56.

55. Kawachi I, Kennedy BP, Gupta V, Prothrow-Stith D. Women's status and the health of women and men: a view from the States. Social Science \& Medicine. 1999;48(1):21-32.

56. Huber E, Stephens JD. Development and crisis of the welfare state: parties and policies in global markets. Chicago: University of Chicago Press; 2001.
57. Bambra C. Cash versus services:'worlds of welfare'and the decommodification of cash benefits and health care services. Journal of Social Policy. 2005;34(02):195-213.

58. Bambra C. Health status and the worlds of welfare. Social Policy and Society. 2006;5(1):53.

59. Waitzkin H. Political economic systems and the health of populations: historical thought and current directions. Macrosocial Determinants of Population Health: Springer; 2007. p. 105-38.

60. Coburn D. Beyond the income inequality hypothesis: class, neoliberalism, and health inequalities. Social Science \& Medicine. 2004;58(1):41-56.

61. Szreter S. Economic growth, disruption, deprivation, disease, and death: on the importance of the politics of public health for development. Population and development review. 1997:693728.

62. Ruhm CJ. Are recessions good for your health? The Quarterly Journal of Economics. 2000;115(2):617-50.

63. Burris S. The invisibility of public health: population-level measures in a politics of market individualism. Am J Public Health. 1997;87(10):1607-10.

64. Muntaner C, Lynch J. Social capital, class gender and race conflict, and population health: an essay review of Bowling Alone's implications for social epidemiology Bowling alone. The collapse and revival of American community. RD Putnam. New York: Simon \& Schuster, 2000, pp. 544, US \$26. ISBN: 068483283 6. International Journal of Epidemiology. 2002;31(1):261-7.

65. Jobert B. Populism and health policy: the case of community health volunteers in India. Social Science \& Medicine. 1985;20(1):1-25.

66. Muntaner C. Teaching social inequalities in health: barriers and opportunities. Scandinavian Journal of Public Health. 1999;27(3): $161-5$.

67. Dahl E, van der Wel KA. Educational inequalities in health in European welfare states: A social expenditure approach. Social Science \& Medicine. 2012. Augments existing welfare regime studies by examining the connections between social expenditures and absolute and relative inequalities in self-rated health across educational levels among 18 European countries. Using data from the EU Statistics of Income and Living Conditions with approximately 245,000 individuals, the authors find that higher social spending is associated with (a) lower health inequalities among both men and women, and (b) lower educational inequalities in absolute and relative health.

68. Eikemo TA, Bambra C. The welfare state: a glossary for public health. J Epidemiol Community Health. 2008;62(1):3-6.

69. Kawachi I, Kennedy BP, Wilkinson RG. Income inequality and health. New York: New Press New York; 1999.

70. Korpi W. Power, politics, and state autonomy in the development of social citizenship: Social rights during sickness in eighteen OECD countries since. Am Sociol Rev. 1930;1989:309-28.

71. Bambra C. Defamilisation and welfare state regimes: a cluster analysis. Int J Soc Welf. 2007;16(4):326-38.

72. Chandola T, Brunner E, Marmot M. Chronic stress at work and the metabolic syndrome: prospective study. Bmj. 2006;332(7540):521-5.

73. Shaw M, Dorling D, Smith GD. Poverty, social exclusion, and minorities. Social Determinants of Health. 1999;2:196-223.

74. Ross NA, Wolfson MC, Dunn JR, Berthelot J-M, Kaplan GA, Lynch JW. Relation between income inequality and mortality in Canada and in the United States: cross sectional assessment using census data and vital statistics. Bmj. 2000;320(7239):898-902.

75. Chung $\mathrm{H}$, Muntaner C. Political and welfare state determinants of infant and child health indicators: an analysis of wealthy countries. Social Science \& Medicine. 2006;63(3):829-42.

76. Siddiqi A, Kawachi I, Berkman L, Subramanian S, Hertzman C. Variation of socioeconomic gradients in children's developmental health across advanced capitalist societies: analysis of 22 OECD nations. Int J Health Serv. 2007;37(1):63-87. 
77. Espelt A, Borrell C, Rodríguez-Sanz M, Muntaner C, Pasarín MI, Benach $\mathrm{J}$, et al. Inequalities in health by social class dimensions in European countries of different political traditions. Int $\mathrm{J}$ Epidemiol. 2008;37(5):1095-105.

78. Borrell C, Palència L, Muntaner C, Urquía M, Malmusi D, O'Campo P. Influence of Macrosocial Policies on Women's Health and Gender Inequalities in Health. Epidemiologic reviews. 2013:mxt002. Systematically reviews the empirical literature on macro-level determinants of women's health and gender inequalities in health. Based on a sample of 19 studies published between 1970 and 2012, the authors find that social democratic welfare regimes, dual-earner family policies, and longer durations of paid maternity leave are associated with improved women's health outcomes. Underscores the importance of macrosocial contexts and policies that narrow unequal gender relations, which have the (unintended) effect of protecting the health of women.

79. Muntaner C, Lynch J, Smith GD. Social capital, disorganized communities, and the third way: understanding the retreat from structural inequalities in epidemiology and public health. Int $\mathrm{J}$ Health Serv. 2001;31(2):213-38.

80.• O'Campo P, Dunn JJR. Rethinking social epidemiology: Towards a science of change: Springer; 2012. Reframes social epidemiology as a 'science of change' by bridging research evidence with direct action, stressing the importance of social change, and introducing new theory and methods to affect public policy changes. Serves as one of the first volumes in social epidemiology to adopt a problem-focused approach (e.g., investigating the macrosocial determinants of health inequaliteis) as well as a solution-focused perspective (e.g., considering how, why, and under what circumstances do social interventions improve living conditions and strengthen public infrastructures).

81. Muntaner C, Borrell C, Espelt A, Rodriguez-Sanz M, PasarÍn MI, Benach J, et al. Politics or policies vs politics and policies: a comment on Lundberg. Int J Epidemiol. 2010;39(5):1396-7. In a debate with Dr. Olle Lundberg, the authors make several compelling arguments relevant to macrosocial epidemiology, including for example: (a) there is no a priori reason to examine the health effects of public policies without explicit consideration of their political origins; (b) universal and egalitarian policies tend to cluster in predictable ways in certain societies and not in others; (c) comparative methods have the power to reveal historical connections between political power and population health; and (d) macro-level studies have the added advantage of potentially identifying intersectoral policies that reduce health inequalities through synergic mechanisms.

82. Lundberg O, Yngwe MA, Stjärne MK, Elstad JI, Ferrarini T, Kangas O, et al. The role of welfare state principles and generosity in social policy programmes for public health: an international comparative study. Lancet. 2008;372(9650):1633-40.

83. Wallerstein I. The capitalist world-economy. Cambridge: Cambridge University Press; 1979.

84. Muntaner C, Lynch J, Smith GD. Social capital and the third way in public health. Critical Public Health. 2000;10(2):107-24.

85. Giddens A, Duneier M, Appelbaum RP. Introduction to sociology: WW Norton \& Company; 2012. Provides a straightforward, accessible, and informative introduction of foundational sociology concepts to public health researchers. Augments the theoretical and knowledge base of social epidemiologists and provides a strong rationale for applying macrosociological perspectives to population health and health inequalities (e.g., understanding how health inequalities are generated and reproduced through relational patterns of social inequality such as social class, and not necessarily through gradational indicators such as income and education).

86. Krieger N, Rowley DL, Herman AA, Avery B. Racism, sexism, and social class: implications for studies of health, disease, and well-being. Am J Prev Med. 1993;9:82-122.
87. Williams DR. Race, socioeconomic status, and health the added effects of racism and discrimination. Ann N Y Acad Sci. 1999;896(1):173-88.

88. Diaz RM, Ayala G, Bein E, Henne J, Marin BV. The impact of homophobia, poverty, and racism on the mental health of gay and bisexual Latino men: findings from 3 US cities. Am J Public Health. 2001;91(6):927.

89. Murray CJ, King G, Lopez AD, Tomijima N, Krug EG. Armed conflict as a public health problem. BMJ: British Medical Journal. 2002;324(7333):346.

90. Levy BS, Sidel VW. War and public health: American Public Health Association; 2000.

91.• Muntaner C, Chung H, Murphy K, Ng E. Barriers to knowledge production, knowledge translation, and urban health policy change: ideological, economic, and political considerations. Journal of Urban Health. 2012;89(6):915-24. Argues that social forces influence knowledge production and knowledge translation. Guided by a social-conflict framework, the authors argue that (a) unequal power relations and health inequalities are causally linked (e.g., some categories of people are healthier than others because they protect their privileges); (b) ideological, political, and economic barriers limit what kinds of knowledge can be produced (e.g., Weber's ethos of scientific objectivity tends to produce research that supports the status quo); and (c) similar barriers exist within the context of policy making, thus preventing real progress toward health equity (e.g., societal tension between egalitarian versus individual values).

92. Chapman S. Advocacy in public health: roles and challenges. Int J Epidemiol. 2001;30(6):1226-32.

93. Gouldner A. The Coming Crisis of Sociology. New York: Basic Books; 1970.

94. Navarro V. Politics and health: a neglected area of research. The European Journal of Public Health. 2008;18(4):354-5.

95. Bambra C. Welfare state regimes and the political economy of health. Humanity \& Society. 2009;33(1-2):99-117.

96. Bambra C, Gibson M, Sowden A, Wright K, Whitehead M, Petticrew M. Tackling the wider social determinants of health and health inequalities: evidence from systematic reviews. J Epidemiol Community Health. 2010;64(4):284-91. Presents a systematic review on the effectiveness of social interventions based on wider, sometimes macro-level social determinants of health. Based on 30 studies identified between 2000 and 2007, the authors conclude that the impact of meso- and macro-level interventions on health inequalities are mixed at best. Although some evidence supports intervening in the areas of housing and work environments, the main take-away is that future public health research needs more intervention studies, and in particular, more work at the macro-level to determine the effects of upstream policies.

97. Habicht J-P, Victora C, Vaughan JP. Evaluation designs for adequacy, plausibility and probability of public health programme performance and impact. Int J Epidemiol. 1999;28(1): $10-8$.

98. Goering PN, Streiner DL, Adair C, Aubry T, Barker J, Distasio J, et al. The At Home/Chez Soi trial protocol: a pragmatic, multi-site, randomised controlled trial of a Housing First intervention for homeless individuals with mental illness in five Canadian cities. Bmj Open. 2011;1(2).

99. Brown P, Zavestoski S, McCormick S, Mayer B. Morello-Frosch R. Gasior Altman R Embodied health movements: new approaches to social movements in health Sociology of health \& illness. 2004;26(1):50-80.

100. Marmot MG, Stansfeld S, Patel C, North F, Head J, White I, et al. Health inequalities among British civil servants: the Whitehall II study. Lancet. 1991;337(8754):1387-93. 